\title{
1 \\ The Paradigm Shift: Disruption, Creativity, and Innovation in Kenya
}

\author{
Bitange Ndemo
}

\section{Introduction}

A paradigm shift is underway in Kenya. New innovations are destroying old ways of doing business, and smart young start-up entrepreneurs are at the forefront of this quiet but historic transformation. Teams of skilled developers and programmers have sprung up in innovation hubs, incubators, and accelerators across the country to build information and telecom solutions that capitalize on the country's mix of challenges and opportunities. At the same time, we have seen a number of spinoffs of Kenya's unique entrepreneurial revolution reach across Africa and into other corners of the world, attracting global recognition for the country.

Digital Kenya addresses the many different aspects of these technological changes, innovations, and entrepreneurial activities, including policy

B. Ndemo $(\bowtie)$

University of Nairobi, Nairobi, Kenya

(C) The Author(s) 2017

B. Ndemo, T. Weiss (eds.), Digital Kenya,

DOI 10.1057/978-1-137-57878-5_1 
formulation, impediments, and opportunities. It is the first book to chronicle the digital entrepreneurship revolution in Africa and describe how it has emerged in the face of high unemployment rates, poverty, lack of technological infrastructure, and disparate cultural interpretations of entrepreneurialism and risk taking. In this context, the book heralds a new way of thinking about and understanding emergent opportunities in the digital world and how best to exploit them in the face of significant developmental challenges.

The book also shows how the paradigm shift that facilitated Kenya's digital revolution was the result of a number of overlapping factors. For one, India's experience and policy framework served as a benchmark and source of inspiration for growth in the face of real challenges. As in India, innovators in Kenya learned that information and communications technology (ICT) had great potential to help propel the country out of unemployment and poverty. The percentage of Kenyans in gainful employment compared with those actively seeking employment has been estimated at 40 percent. The World Bank reported that of the Kenyan 800,000 youth (ages 15-35) that join the labor market every year, only 50,000 secure a job. Some 70 percent of them are unemployed. But rather than view youth unemployment as the ticking time bomb it is often described as, a number of innovators have used the platforms created by ICT as a strategy to absorb large numbers of well-educated unemployed youth and thus to contribute to economic growth. Digital Kenya reviews the many different ways this was achieved and the challenges faced along the way.

In addition, the book describes the development of pro-entrepreneurialism policies and partnerships in Kenya. A simple five-point policy became a key driver of the shift-focusing on the development of ICT infrastructure, leveraging of ubiquitous mobile platforms to build applications, creation of local content, building of human resource capacity, development of public-private partnerships, and creation of employment opportunities for the growing youth population-with the result that Kenya's policy environment has slowly become a conduit for successful ICT development.

The laying of the first fiber-optic cable on the Eastern Seaboard of Africa, the TEAMS cable, it will be shown, was another crucial step and heralded a new chapter for cheaper telecommunication access. With it, opportunities to mainstream Internet access were created, such 
as subsidizing broadband for all universities and creating start-up hubs where entrepreneurs had access to high-speed Internet.

Soon new Web applications (apps) were being created. M-PESA, the money-transferring app, capitalized on the fact that only 5 percent of the Kenyan population had access to bank accounts and created a solution that revolutionized citizens' financial freedom. The post-election violence of 2007-2008 also brought some unexpected innovation when a small group consisting of Erik Hersman, Ory Okolloh, Juliana Rotich, and David Kobia began to collect eyewitness reports of violence from emails and text messages and upload them to Google Maps, giving rise to Ushahidi (Swahili for "testimony" or "witness"), a groundbreaking information-gathering, visualization, and interactive mapping tool that is now used around the globe. Ushahidi, along with M-PESA, changed the minds of even the doubters that it was possible for innovation to stimulate world-class entrepreneurialism in Kenya.

Although the landing of the cable was a foundational step in Kenya's emergent entrepreneurial revolution, the opening up of public data was equally important. Kenya developed the Kenya Open Data Initiative, a portal to fuel new apps and new enterprises. Civil society, through the online discussion portal KICTANet, began to push for additional data sets and raised many additional policy issues beyond a mere call for data. Other factors, such as investments in research and seed capital for social enterprises provided by institutions such as the Rockefeller Foundation, propelled Kenya's many ICT programs and projects in ways that involved and empowered the less fortunate.

\section{The Purpose}

Digital Kenya seeks to bring into perspective the ongoing debate about adoption of disruptive ICTs not just in Kenya but throughout the world. Kenya is not new to disruption, considering the fact that our own innovations, such as M-PESA, Ushahidi, BRCK, and BitPesa, are causing disruptions in other parts of the world-and that many more Kenyan-led innovations are underway. To ensure that Kenya and Africa continue to contribute to this important growth, we must open up the conversation 
about entrepreneurialism and risk and be supportive of disruptions coming from elsewhere. The ICT revolution is a global and competitive phenomenon that is heralding a new paradigm of creativity and innovation in virtually every part of the world. In fact, by the time this book goes to press, there will be hundreds of new apps on the market and nations newly acceding to disruptive change-alongside new movements to restrict rapid technological advancement.

It is hoped that the book will help policymakers approach policy differently than they have done in the past. Looking at policy from various perspectives - such as the entrepreneurial approaches explored in Chap. 1, "Inside a Policymaker's Mind: An Entrepreneurial Approach to Policy Development and Implementation," by the author of the present chapter (and co-editor of the book) — as a strategy for dealing with some of the more pressing challenges could revolutionize how we tackle development challenges in general and help the world make real progress toward the United Nations' Sustainable Development Goals. Opening access to hospital registry records, for example-which can help researchers discover new patterns of diseases and ultimately improve health systems across the globe-is one such strategy.

When historians write Africa's digital story, Kenya will likely assume its place as the cradle of ICT revolution on the continent. Never before has an African nation gone through a disruption such as the digital transformation that is still underway in Kenya. With so much creativity and innovation going on, the nation is witnessing a gigantic paradigm shift. It is a revolution of a kind that is empowering ordinary citizens and reshaping their communities and lifestyles, heralding a new way of thinking about and understanding entrepreneurial opportunities and how to exploit them.

\section{Chapter Overview}

Digital Kenya investigates the power of technology in Kenya to help strengthen every sector and of entrepreneurship as the key driver in innovation creativity and disruption. The book records the so-far-undocumented story of technology start-ups, entrepreneurship, and policymakers that have been on the forefront of ushering in a new era for Kenya. 
The words "creativity" and "innovation" were uncommon in Kenya and in Africa until the advent of the digital age and thus mark how far we have come. In 1982, the Kenyan government banned the use of computers in public offices for fear that the new technology would take away secretarial jobs. Today, virtually every public office has computers - with more people than in the past engaged in their use-to enhance service delivery. Chapter 2, "The Internet Journey for Kenya: The Interplay of Disruptive Innovation and Entrepreneurship in Fueling Rapid Growth," by Muriuki Mureithi, takes us back to this time and gives the historical background of the foundation of the digital revolution in Kenya. In doing so, it describes the evolution of the digital enterprise and also presents the significant challenges of the day, including new competition, changing customer engagement and business models, unprecedented transparency, privacy concerns, and cybersecurity threats.

Although most research on the role of the digital economy in economic development has focused on the "digital divide," Chap. 2 also describes how new research is linking digital transformation to faster economic growth in much the way the Asian Tigers (Hong Kong, Singapore, South Korea, and Taiwan) did with industrialization. African countries have incorporated (information and communications technology - or technologies) ICTs in their development planning—or "vision"-policies. Kenya's Vision 2030, for example, promotes ICT as one of the flagship areas to help the nation realize its vision.

Chapter 3, "The KINGS of Africa's Digital Economy," by Erik M. K. Osiakwan, describes the history behind the frontrunners in ICT transformation in Africa: Kenya, Ivory Coast, Nigeria, Ghana, and South Africa, designating them as the "KINGS." The chapter argues that, like the Asian Tigers, the KINGS will lead the continent's technology innovation, thanks to their rapid growth and high-tech entrepreneurship, setting the pace for the rest of the continent.

\section{Market Opportunities}

Africa presents a sea of economic opportunities in virtually every sector, and the continent's (comparatively youthful) population structure compared with that of other parts of the world is an enormous opportunity 
in this digital era. The demand for online services is increasing, including the digitization of records to improve data visibility. These are all areas that will require a young, educated population — which is now abundant in many African countries. Chapter 4, "Addressing Voids: How Digital Start-ups in Kenya Create Market Infrastructure," by Marissa Drouillard, seeks to unlock the hidden market opportunities presented by marketenabling digital platforms. It reviews various market-enabling digital platforms in Kenya brought to light through research on digital entrepreneurship ecosystems, finding examples where Kenyan digital start-ups have achieved success in breaking down traditional barriers and offering better value propositions to customers.

The combination of knowledge and technologies makes a powerful tool for change. Chapter 5, "Reimagine What You Already Know: Toward New Solutions to Longstanding Problems," by Jay Larson and Michael Munger, argues that knowledge and technology combined can change societies dramatically, creating opportunities that were previously unthinkable. African nations now stand on the threshold of revolutionary changes based on ICTs, especially mobile platforms, and the chapter makes a strong case for why education needs to be reimagined from the ground up. Once society takes education out of the four walls of the traditional classroom into homes, libraries, Internet cafés, and city streets, a completely new learning experience becomes possible-an experience that innovators need to harness now in order to leverage our digital potential.

The private sector has had interesting engagements with the ICT sector in Kenya, specifically through social entrepreneurship. Chapter 6, "I-Entrepreneurship: Changing Lives through Technology," by Carmen Merab Wamukoya and Amolo Ng'weno, examines the growth of social entrepreneurship in Kenya and demonstrates how businesses can create shared value in the field of technology. It illustrates the role of impact sourcing as a means of generating employment through an examination of Digital Divide Data, Kenya's innovative ICT program for the training and education of disadvantaged youth. It also reviews the potential of ICTs to transform businesses and provide an enabling environment for the development of technology-based social enterprises. 
Customizing a complex technology to local environments makes it simpler and more relevant even in the most unexpected areas. Today, even the poorest citizens in shantytown areas participate in social media, which has given rise to new approaches to communication. Chapter 7, "From Cyber Café to Smartphone: Kenya's Social Media Lens Zooms In on the Country and Out to the World," by Mark Kaigwa, explores the expressions of the "connected Kenyan." Often used by Kenyans online, it is the common denominator in all of the other chapters of the book. It seeks to answer questions such as what happens once a Kenyan comes onto the grid of Internet connectivity - be it smartphone or cyber. What is his or her experience, how do they find their way, and what becomes important to them? What is to be said for the digital spaces of community and expression that have emerged and become part of the fabric of how information now travels? The chapter addresses these questions and argues that it is not enough to be connected: It is also how you are connected and how the news, for instance, finds you that defines the depth of ICT penetration in a community.

\section{The Inner Life of Technology Entrepreneurship in Kenya}

To foster greater opportunity, Kenya has sought to develop an ICT ecosystem — which was soon dubbed the "Silicon Savannah"—in Konza, 60 kilometers south of Nairobi. This project seeks to address the problems of disjointed development, in which research communities rarely interact with industry, for example, and even less with policymakers. Chapter 8, "Building ICT Entrepreneurship Ecosystems in Resource-Scarce Contexts: Learnings from Kenya's 'Silicon Savannah,' by Johannes Ulrich Bramann, explores how ICT entrepreneurship ecosystems can be established in resource-scarce contexts, such as a scarcity of financial resources, established ICT sectors, and relevant human capital. It sheds light on the evolution of Kenya's ICT ecosystem and examines the barriers and subsequent enabling processes encountered when growing an ICT ecosystem in a resource-scarce context, providing a holistic perspective 
on the barriers and enablers encountered in the areas of culture, human capital, finance, policy, entrepreneurial support systems, and markets.

Many countries in the Global North offer a variety of incentives for start-ups. Yet African countries have not, so far, been able to encourage or support start-ups in the same way. Chapter 9, "The Challenges of Technology Entrepreneurship in Emerging Markets: A Case Study in Nairobi," by Marlen de la Chaux and Angela Okune, investigates why the creation of technology start-ups in Nairobi has remained challenging despite support from an increasing number of innovation hubs and seed capital investors. The authors look at three different groups-entrepreneurs, innovation hubs, and seed capital investors - and expose the divergent views among these groups that lead to contradiction, misalignment, and ambiguity in Kenya's ICT industry. De la Chaux and Okune attribute this phenomenon to the fact that the industry is still in an emergent state, with the result that the many stakeholders hold divergent views on the exact challenges - in the areas of finance, skills, and market readiness, for example_-and how they need to be addressed, thereby inhibiting the development of a shared agenda for growth.

Chapter 10, "Organizational Cultural Hybrids: Nonprofit and For-Profit Cultural Influences in the Kenyan Technology Sector," by Eleanor R. Marchant, builds the case that in order for progress to take place in the Kenyan technology sector, we need to move beyond the stale debate about whether non-profit grant funding is good or bad-and instead find ways to take advantage of the multiculturalism that exists in the sector. The chapter draws on existing theories about culture at organizations to demonstrate that even incubators, often associated with the for-profit model that dominates the discourse, are not purely for-profit when they are examined more holistically using the lens of cultural theory. Using Schein's theory of the three levels of organizational culture-that is, observed behaviors and artifacts, espoused beliefs and values, and underlying assumptions - the chapter demonstrates in a more nuanced way that cultural hybridity exists at key organizations in Kenya's technology sector and how practices and behaviors of these organizations are shaped by their fundamental underlying assumptions. 


\section{Managing the Fine Details of Doing Business in Kenya}

There are no longer confused arguments about why a country would, or would not, seek an ICT-enabled transformation. As Nagy Hanna in Mastering Digital Transformation: Towards a Smarter Society, Economy, City and Nation explained, it is "through ubiquitous connectivity, digitization of content and processes, crowdsourcing, collaborations, tools, knowledge networks, sensors, data capture and sharing, artificial intelligence, and analytics, [that] ICT can help build innovative enterprises, mobilize local knowledge and problem solving, and make global knowledge accessible to all. ICT can network actors and organizations across sectors and regions, build collaborative platforms to co-create development solutions, and enable client-centric service delivery." To achieve these benefits, there must be good leadership and an enabling dynamic policy environment.

Chapter 11, "Inside a Policymaker's Mind: An Entrepreneurial Approach to Policy Development and Implementation," by the author of the present chapter, offers an analysis of the policy process that led to the ICT boom in Kenya during President Mwai Kibaki's administration (2003-2013) and of the policy developments that spurred the highly successful innovations in the country's ICT sector. The chapter explains the course of establishing the institutions that supported ICT entrepreneurship and describes the process involved in the making of far-reaching policies and analyzes, using three case studies in ICT policy development - the TEAMS fiber-optic cable project, the M-PESA application project, and the Posta land development project-and discusses their contributions to Kenya's ICT boom, arguing that if there is any lesson to be learned from the Kenyan experience, it is that political will is by far the most important aspect of policy development. Countries in the Global South are replete with failed projects, in part because of a lack of political will. The chapter also describes how other factors, such as pro-activeness, innovative outside-the-box thinking, and an appetite for risk, played key roles in the success of the Kenyan ICT transformation process. 
International organizations seeking to collaborate with local organizations need more than an enabling policy environment. They also need to understand local dynamics. Chapter 12, "The Art of Managing Worldviews in Kenya's International Technology Sector," by Tim Weiss (co-editor of the present volume) and Klaus Weber, documents what a prospective investor needs to do to become successful in Kenya's tech scene. It investigates if there is such a thing as a Kenyan recipe-a holy grail-for success. The research brings into focus two different worldviews, a "Kenyan worldview" and an "international worldview," that stand on different sides of the question of how to do it "right." This dynamic sheds light on the contested issues that have surfaced during Kenya's international tech boom. However, it also shows that tension and contestation, if tackled with the right mindset, can also become opportunities. The chapter thus introduces the art of managing worldviews in order to help equip actors with new tools to work through challenges and infuse technology entrepreneurship with a unique Kenyan character.

Chapter 13, "Developing Strategies to Harness the Power of Parallel Entrepreneurship in Africa," by Eskor John, identifies some of the most salient factors related to parallel entrepreneurship_-factors that, if better understood and supported, have the potential to make a significant contribution to the transformation of Global South economies. It also explores the contextual factors contributing to the growth of entrepreneurship in Africa and the prevalence and implications of parallel entrepreneurship. It concludes with a number of recommendations on how to support and develop parallel entrepreneurship in other contexts and countries.

The success of an enterprise depends on the ecosystem in which it operates. Leveraging primary and secondary sources, Chap. 14, "Venture Capital in East Africa: Is There a Right Model?," by Stephen Gugu and Wilfred Mworia, seeks to establish if there a right model for venture capital in East Africa, concluding that the ideal model does not currently exist. The study suggests that the high cost of operating a fund in the region and the length of time it takes to find, evaluate, and make investments are the top concerns among fund managers. In addition, fund managers in the region are called upon to take on roles that are atypical of conventional fund management, including, in particular, getting heavily 
involved in investees' businesses. The authors conclude that in order to succeed, venture capital needs to adapt more effectively to suit the context and characteristics of venturing in the region.

In Chap. 15, "Entrepreneuring for Society: What is Next for Africa?" by Tim Weiss (co-editor of the present volume), the author weaves the chapters of the book and the conversations with thought leaders into a single narrative. He highlights key issues and trends, among them a profound mindset change that is underway in Africa, affected through selfawareness and pro-activity. He goes on and revisits the cultural impact of state and non-governmental organisation (NGO) dependency, something that has been a critical barrier to innovation on the continent. In his critical inquiry on the entrepreneurial revolution he also asks: Which traditional norms and values should remain and which new ones should be incorporated and adopted to foster-rather than impede_-societal development? Weiss then continues and expands on the mythical character inherent in the information age that exposes the deeper wish to level the playing field through digital solutions albeit power continues to remain in the hands of a few global companies. This fallacy, however, he argues should not stop us from resolving challenges in the education sector, and advancing social impact. Rather a calls for a mindful creation and implementation of innovations, critically assessing the intended and unintended consequences of change. He concludes with a roadmap for the years ahead, and with that introduces an intriguing discussion that places Africa's response to various grand global challenges on the center stage.

\section{Summary}

Our aim with this book is to generate debate on the role of ICTs in economic development through entrepreneurship. It is also intended to create awareness of the emerging opportunities in ICT and to present new ways of exploiting them. There is no doubt that ICTs are changing the African narrative: Africa is no longer the Dark Continent. Africa is rising. The rate of change in Africa today as a result of ICTs is unprecedented and cuts across all sectors. From innovations such as M-PESA to largescale business process outsourcing developments, ICTs are creating jobs, 
addressing poverty, reducing inequality, and providing mechanisms to monitor and address the Sustainable Development Goals. Governments are becoming more productive, farmers are getting value for their produce, transportation is becoming more efficient, and education is increasingly accessible and practical. External stakeholders are noticing, too. Multinational corporations are increasingly setting up research laboratories in Nairobi, and international policymakers are coming to Kenya to learn how we did it. These are just a few examples of ICT's impact in Kenya. There will be even more promise if we continue to adopt ICT instead of fighting it.

We hope that Digital Kenya will serve as a resource for those wishing to better understand the genesis of Kenya's ICT boom for policy, practice, and research. 


\title{
Conversation \#1
}

\section{The Past, Present, and Future of the 'Digital Nyika': How to Fix an Aircraft in Flight}

\author{
Jimmy Gitonga of Afroshok Media
}

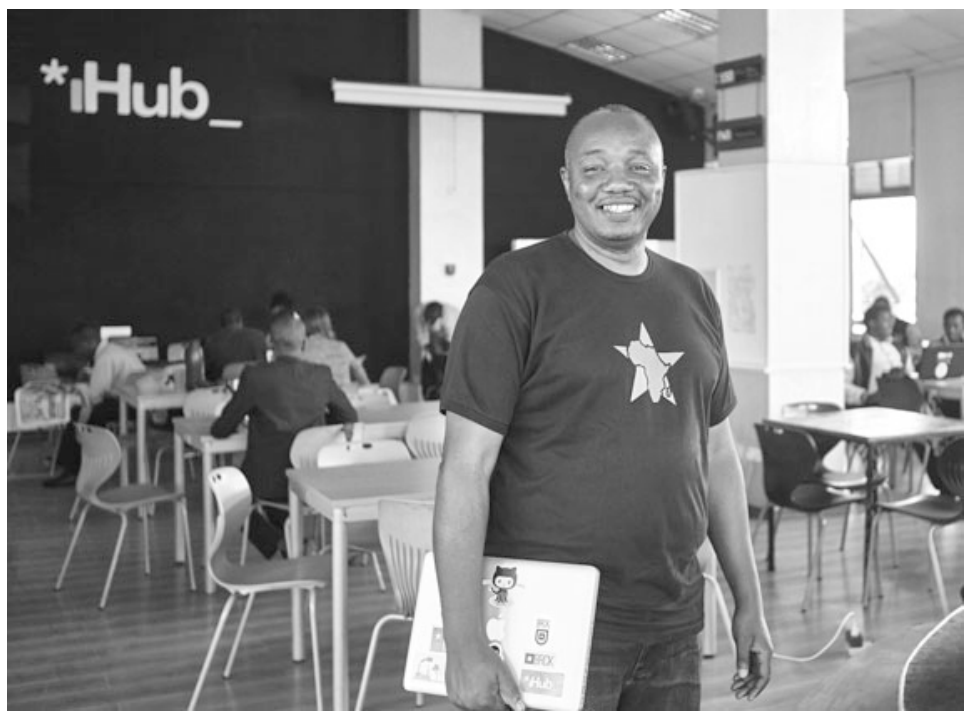

Jimmy Gitonga took the scenic road to getting here. Having studied physics and applied mathematics at the University of Nairobi, he then studied electronics at Kenya Polytechnic. He ran a consumer and professional electronics firm, Audiophilia Electronics, that was involved in designing and installing a radio broadcast studio for WorldSpace (a global satellite radio network). 
He then veered into graphic design, web design, Flash development, and motion graphic - after which he went into animation, working on the pilot project of the British-Kenyan children's television series Tingatinga Tales. Jimmy is a founding member of the ARK, a design house that developed the Zuku brand for the Wananchi Group and designed the iHub space. He was also a past iHub community lead, overseeing the growing membership base, and targeted programs toward team members, start-up, and how these members can deliver solutions to the enterprise and public sectors in Kenya and across Africa. Today, Jimmy runs Afroshok, his own boutique design firm, and is an iHub ambassador involved in community projects.

\section{Jimmy, what fascinates you about digital technology in Kenya?}

Recently in Kenya, we witnessed a moderately sized exit through the purchase of a technology start-up at about USD1.7 million. ${ }^{1}$ Several months later, we had another kind of tech start-up exit, not in realization of dollars but in a failure of top management, brought about by what I would call culture and vision fit issues. ${ }^{2}$ During this period, I attended a number of seminars and industry events, and I began noticing interesting trends that affect how we, as Kenyans in particular and as Africans in general, are interacting with digital technology and the proliferation of digital products.

Let us look at this in more detail. In Kenya, we can see a cultural transition happening as the generation that witnessed the independence of the country moves off the stage. The generation born between 1970 and 1980 saw the political realignment that came after the Cold War and has now grown up. Apartheid and its proxy wars came to an end as propped-up countries like Somalia and Yugoslavia collapsed. In the 1990s, Mandela became a global icon because of the Internet and easy access to it through personal computers. The personal computer and the Internet came to Africa especially with the backdrop of these global political realignments. Remember, the electronics giant Apple could not sell a certain model of computers to so-called "enemy states" of the USA. The mobile phone arrived on the scene in the 2000s, and now so has cyber-warfare, where

\footnotetext{
${ }^{1}$ See Moraa, Hilda. 2015. A Kenyan Startup Journey: My 10 Key Lessons.

${ }^{2} \mathrm{See}$ https://medium.com/@brendawambui/corruption-in-the-silicon-savannah-9e393a00aa0e\# .8 uz9dnugf.
} 
politically opposed countries have taken their differences online. So the place of governments and the ICT sector are intertwined.

For most Kenyans, the mobile phone and the Internet arrived together-and the people picking up these two technologies are mostly below 35 years of age.

\section{Jimmy, what would you say were the key milestones that brought Kenya's ICT sector to where it is today?}

I handled my first computer at the University of Nairobi. There was no degree in computer science then, just a post-graduate diploma. For programming languages, we studied Basic, FORTRAN, and COBOL. We worked on Wang terminals connected to the university's mainframe. I finished at the university and joined Kenya Polytechnic for a transition course to electronic engineering, where we studied everything related to "light [electrical] current" technology. I was equipped for the computer age in Kenya. The pre-Internet software development industry was also gaining traction at the time, with names like Lotus, FoxPro, and Dbase coming in.

Around this time, the Internet landed visibly in Kenya through a company of young Turks called Africa Online and an older-guard company called FORM-Net Africa. Almost anyone who has become prominent in the Internet space in Kenya came from or passed through these two companies. One thing that did not happen is the landing of fiber-optic cables on the East African coast. The cables went round Southern Africa, passing Mauritius and landing in India. Kenya and other Eastern Africa countries would have to rely on expensive satellite Internet connections for another decade.

At the same time, most of Africa was in political upheaval as the Cold War period closed with the emergence of "multi-partism" and human rights. These were attached to the Bretton Woods institutions' Structural Adjustment Programs (SAPs) that were implemented from the 1980s onward. The SAPs wiped out most of the social facilities that African countries had created after their independence. In Kenya, health and 
education were hit hard. A system called Cost Sharing was introduced. A lot of people who had already been hammered by falling prices of local goods, due to liberalized markets, could not afford medication for their babies or schooling for their children.

The real Kenyan economy shrank relative to population growth with rural-to-urban migration growing earnestly. Nairobi's population grew by over 61 percent between 1989 and 1999, compared with a 34 percent growth in the entire country. This is the time that Microsoft's Windows 95 spread and with it the Microsoft Office suite of packages. Computer manipulation skills were in demand, creating a market for computerrelated training that was colloquially known as "learning packages." This fed the need for alternative tertiary training for the urban immigrants and school-leavers as well as bringing current management executives in many companies up to digital speed.

By the time the Internet 1.0 dot-com bubble burst, in 2001, Kenya entered into a "Second Liberation" political era, with the end of the rule of the political party that had been in power for close to 40 years. Foreign investment and the effects of the privatization of state corporations continued, with the entry of mobile telephony networks in Kenya as well as most of Africa. Safaricom, a spin-off from the state corporation Telkom Kenya, brought in affordable mobile connectivity to a country that had slightly over 320,000 fixed lines at the time. By 2002, there were 500,000 mobile phone users, and the growth has been in double-digit percentages ever since.

At this time, the Kenyan government removed importation-related taxes on mobile devices and computers. This allowed almost anyone to afford a mobile phone, and laptops began to be a common site at universities. Kenya's then Permanent Secretary in the Ministry of Information and Communication, Doctor Bitange Ndemo, led a move to break away from the bureaucracy-plagued Eastern Africa Submarine Cable System and set up The East African Marine System (TEAMS) consortium. Once launched in 2009 and after a number of cable mishaps, the TEAMS 
cable has upgraded its designed capacity from 640 Gbps to the current 1200 Gbps, and Kenya_along with most East African countries_uses this cable because of its better transmission quality and reliability. Other cables have come in, too, leading to a total of four fiber-optic cables in Mombasa. Access to the Internet has become a reality for many people.

In 2007, Vodafone, through Safaricom, launched the M-PESA money transfer platform. Since then, M-PESA has become the global leader in mobile money transfer and raised the possibility of Kenya and Africa being at the forefront of world m-commerce. Just a year later, the crisis crowdsourcing platform Ushahidi was created to monitor the increasingly opaque Kenyan election scenario in early 2008. This platform then went on to become a globally recognized and used way to monitor crises.

In 2010, the first tech community-led "hub" was opened. The iHub, which stands for "innovation Hub," is a co-working and hacker space and, in its own words, "a nexus for technologists, investors, young entrepreneurs, designers, researchers, and programmers." The iHub was the pioneer among the numerous co-working and incubation spaces across Africa today. It is here and in other African technology, art/culture and co-working spaces that the question of the global positioning of the African digital entrepreneur began to be raised.

If Africa Online and FORM-Net Africa formed the first wave of digital entrepreneurs and companies, these four events - the Kenyan government's genuine commitment to ICT, the M-PESA platform, Ushahidi, and the iHub-were the milestones in the making of the Kenyan technology landscape (with its new moniker, the Silicon Savannah).

\section{What do you think of the Silicon Savannah's future? What can we expect?}

That is a good question. And such questions have started to be posed in the expounding of the vision of the Silicon Savannah. Is it possible or is it a dream, driven by the hype of tech-savvy Kenyans? Are these dreams realistic? What will it take to put Kenya and Africa on the global 
technological map? In Kenya, again, you can see the two parties in it, the government with its politico-economic agenda and the people's relationships with this as they go along doing their business.

As the initial media spotlight continues to dim, a number of fundamental issues about business anywhere are becoming apparent. Kenyan entrepreneurs do not yet have the requisite knowledge and commercial infrastructure to build globally recognized technology companies when compared with their Western counterparts. What is being asked of them is equivalent to fixing an aircraft while yet in flight. Not only is the global technology landscape changing rapidly, but African entrepreneurs are being asked to stake their claim as it changes. And if that is based on the timeline of California's Silicon Valley, then we are 50 years late to the party.

\section{Being late to the party is one thing. But what are the underlying issues at play?}

Africans seem to have a penchant for accepting foreign ideas and absorbing them without critically investigating their source, history, necessity, and workability in the context of the African space. Look at the words being used in the African technology environment-words like Silicon Savannah - and you can see that not a lot of thought was put into the connotation, as if the perception of the American Silicon Valley had been taken wholesale and simply plastered onto an African scenario. This way of thinking started some time ago, and Silicon Valley is just the most visible part of that iceberg.

Stepping back a bit, Africa's destiny in the world began much earlier and changed significantly in the 1500s, when the Portuguese began sailing to Africa. At that time, Africa south of the Sahara could stand toe-to-toe with Europe in social, commercial, and military prowess. The Portuguese became the most active Europeans in Central Africa and met the Kingdoms of Kongo and Ndongo, among others, that were as good as the Portuguese were in diplomacy, war, and commerce. The Portuguese carried out the business of slavery in earnest to provide for the labor necessary to conquer the new colony of Brazil. 
In order to gain a foothold in the kingdoms of Benin, Kongo, and Ndongo on the African western coast, a number of missionaries were sent to "Christianize" the Africans. One of the most important concepts was that "slavery was a normal part of world affairs"- a European Christian construct and a position favored by King Afonso I, ruler of the Kingdom of Kongo (1456-1543). ${ }^{3}$

The Portuguese slave traders had a plan. As the people became "enlightened" by Christian education, communities were convinced to rebel against Afonso's rule. The ensuing rebellion would be used as an excuse by the Portuguese to wage war against these communities in the name of aiding Afonso, thus creating prisoners of war who invariably added numbers to the slave trade. Before long, Afonso's kingdom was falling apart, his authority diminished, and some areas became depopulated. This was a strategy used again and again across Africa by the "other" Europeans.

The Industrial Revolution took this state of affairs to an even higher level. With the "Scramble for Africa" and colonialism, Africa fell behind the development of the European and later American and Asian nations in world affairs. Globalization picked up speed, accelerating in the twentieth century because of two World Wars and electronic communication. Now, in the twenty-first century, globalization is spreading at the breakneck speed of the Internet and the mobile phone.

Today, in the post-Industrial Age, a new concept has emerged-that of the digital entrepreneur. These two words carry a different emphasis, depending on whether you use the Western or African perspective. In the West, "entrepreneur" is massively important right now because it virtually disappeared during the Industrial Age. Before that, everyone was an entrepreneur. In Kenya, particularly, almost everyone is still an entrepreneur. It is the "digital" that is new. This means that in the future, formal

\footnotetext{
${ }^{3}$ See 'Portuguese and other Europeans in Africa in the early 1500s,' http://www.fsmitha.com/h3/ h17port2.htm.
} 
employment, especially in ICT, will increasingly be seen as an option to an "informal" vocation or a transition to self-employment.

But this state of affairs is not spread evenly across Africa. Canal+, a French media company, held a conference in Nairobi where I participated as one of the organizers. Delegates from French-speaking countries in Africa were invited to understand how ICT hubs are spreading throughout Africa and the possibility of this happening in their countries in particular. As we talked about thinking outside the box, it became clear that most of French-speaking Africa lags behind the English-speaking communities in digital entrepreneurship, because the France-based education system follows the old paradigm of standardized learning, in which innovation is not encouraged. An entrepreneur needs critical thinking, persistence, adaptability, creativity, and initiative. The situation is not helped much by the fact that most Western technological ideas are shared on the Internet in the English language.

\section{What is the way forward for the future of digital technology in Africa?}

Let me give you an example. Africa is still portrayed in Western media as if we were in the sixteenth century. Adding post-colonialism and the international aid guilt trip, Africans are relegated to handouts that come in many forms while the extraction of minerals and human resources continues. Africans consume the messaging that they must take what they are given and become entrapped by Western ideas and ideology. This leads to collective low esteem and apathy, creating passive people who are absent from the conversations that affect them on the world stage.

There are things we as Africans can learn from our history when looked at from a Western worldview. But as Minna Salami, an African writer said, "These images are so negative that it takes us tremendous effort to not see ourselves through the eyes of this distortion." ${ }^{4}$ It will take a lot of work and some time for the Western worldview of Africa to clear.

\footnotetext{
${ }^{4}$ See Minna Salami. 'To change the world, change your illusions'; https://www.youtube.com/watc h?v=PiVB5niLrWg\&feature=youtu.be.
} 
In this digital era, African entrepreneurs need to see themselves clearly and consider a different, bolder perspective as they strike out to make their mark in the world. We need to reinvent Africa and use digital technology, the mobile phone, and the Internet to do it. Just as most of Europe is defined through the Industrial Revolution ("German engineering," etc.), perhaps African communities can be defined and reimagined through the lens of digital technologies.

\section{What are some of the lessons, implications, and changes in mindset that you think are necessary?}

Allow me to propose three lessons that we need to take from our history. First, we must remove our Western-colored view of Africa and look at it in a new way in order to create a conducive environment. Individualism is the lens through which people in the West view themselves. We must recognize that we Africans base our social outlook on collectivism. This immediately explains the differences in approaching the identification of innovative solutions. For the West, innovation stems from solving concerns revolving around the individual. In Kenya, the innovations that have been built are to solve non-individual problems.

Before M-PESA, there was Sambaza. This was-and still is-a service designed to allow one person to buy mobile phone airtime for someone else, say, a son in the city buying for his mother, who lives up-country. The problem was that the airtime was sold in large denominations, even though most subscribers wanted small amounts at a time. So, enterprising Kenyans would buy the large-denomination cards, usually for 100 Kenyan shillings or more, and resell airtime to others in smaller amounts, charging a fee for the service-with the result that using a service developed for one purpose created opportunities for another. M-PESA took advantage of this enterprising nature, allowing two individuals to transfer money to each other and Safaricom to make some money off that, unlike in the Sambaza system. Safaricom then produced small-denomination airtime cards branded as Bamba. M-PESA and Bamba cannibalized Sambaza. This mobile commerce innovation was based on non-individual needs. The same non-individual premise could be attributed to Ushahidi, the company that I talked about at the beginning. And so, we 
should expect more non-individual and social innovations to come from Africa (mobile banking and retail have already taken hold).

Second, the initial innovations in Silicon Valley focused on "silicon" based ideas. It was used in the production of electronic components and microcircuits. Some of the companies involved were Shockley Semiconductor Laboratory and Fairchild Semiconductor, from whom Intel and Advanced Micro Devices, among others, were spawned. These innovations were taking place in the Santa Clara Valley in San Francisco. It is these innovators who "developed a culture of openly denying the hierarchical culture of traditional corporations. People remained faithful to each other, but not to the employer or the industry." 5 This is Silicon Valley.

We need to recognize this, because nowhere in Africa is silicon itself being used to innovate through production. Africans are joining this innovation space during the digital — and, more correctly, the mobileera. So "digital" is a better description of African innovation at this time. Also, though "savannah" is used to depict an African landscape, it is not an African word. It comes from a Native American community for the grassland prairies they inhabited. ${ }^{6}$ Should we not be using the name that Africans themselves gave their grasslands? - Nyika!

This renaming — "Digital Nyika"-even though a seemingly small change, is an exercise that forces us to look at the African innovation space without biases. We can then learn from other innovative spaces around the world, copy what is necessary, build what infrastructure we need, and innovate for Africa first. Only then can uniquely African knowledge and financial investment grow in an environment that is in itself unique.

Third, it should be noted that most of the tech solutions that have come out of Africa and ventured onto the international stage had a local problem at their core. That is all well and good. But the current Silicon

\footnotetext{
${ }^{5}$ Access Wikipedia. 'Traitorous Eight'. https://en.wikipedia.org/wiki/Traitorous_eight for more information.

${ }^{6}$ Access Wikipedia 'Savanna', https://en.wikipedia.org/wiki/Savanna for more information.
} 
Valley thinking in Africa has caused the ideas we see coming out of our innovation space to be mostly copies of what we see in America and other places, with the only new ingredient being "How can it work here?" Still, Ushahidi is an example of a global problem solved first locally. There was no other solution like it nor would there have been one, because the conditions for its creation were unique to Kenya and other developing economies.

Africa in space and time must take charge of its destiny, using digital technology to take advantage of the confluence of a young and growing demographic, an increasingly multipolar political world, and all the advantages of not being saddled with generally older populations and analogue technological systems. If you look around, this is already taking place-and is increasingly crossing over to innovations that combine software and hardware.

That is our Kenya, a new Africa, the birthplace of mobile money and crisis maping.

What will be next?

Thank you, Jimmy!

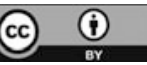

This chapter is distributed under the terms of the Creative Commons Attribution 4.0 International License (http://creativecommons.org/licenses/by/4.0/), which permits use, duplication, adaptation, distribution and reproduction in any medium or format, as long as you give appropriate credit to the original author(s) and the source, provide a link to the Creative Commons license and indicate if changes were made.

The images or other third party material in this chapter are included in the work's Creative Commons license, unless indicated otherwise in the credit line; if such material is not included in the work's Creative Commons license and the respective action is not permitted by statutory regulation, users will need to obtain permission from the license holder to duplicate, adapt or reproduce the material. 